\title{
Electrochemical Corrosion Behavior of Fe64/Ni36 and Fe55/Ni45 Alloys in 4.0\% Sodium Chloride Solutions
}

\author{
El-Sayed M. Sherif ${ }^{1,2, *}$, Hany S. Abdo ${ }^{1,3}$, S. Zein El Abedin ${ }^{2}$ \\ ${ }^{1}$ Deanship of Scientific Research, Advanced Manufacturing Institute, King Saud University, P. O. Box \\ 800, Al-Riyadh 11421, Saudi Arabia \\ ${ }^{2}$ Electrochemistry and Corrosion Laboratory, Physical Chemistry Department, National Research \\ Centre, El Bohouth St. 33, Dokki, P.O. 12622, Giza, Egypt \\ ${ }^{3}$ Mechanical Design and Materials Department, Faculty of Energy Engineering, Aswan University, \\ Aswan 81521, Egypt \\ *E-mail: esherif@ksu.edu.sa
}

doi: $10.20964 / 2017.02 .58$

Received: 30 October 2016 / Accepted: 6 December 2016 / Published: 30 December 2016

The electrochemical corrosion behavior of two iron/nickel alloys namely, Fe64/Ni36 and Fe55/Ni45, in $4.0 \% \mathrm{NaCl}$ solution was reported. The study was conducted using open-circuit potential, electrochemical impedance spectroscopy, cyclic polarization, and chronoamperometric current-time measurements. The surface of the alloys after 7 days immersion in the solution was investigated by scanning electron microscope and energy dispersive X-ray analyzer. It was found that the corrosion resistance for Fe55/Ni45 alloy was higher than that for Fe64/Ni36 one. This was confirmed by the low corrosion current and corrosion rate as well as the high corrosion resistance for Fe55/Ni45 compared to Fe64/Ni36 alloy. Moreover, the less negative potential and the low absolute current obtained for Fe55/Ni45 alloy by the open-circuit potential and chronoamperometric experiments, respectively.

Keywords: corrosion; iron-nickel alloys; polarization; EIS; chronoamperometry

\section{FULL TEXT}

(C) 2017 The Authors. Published by ESG (www.electrochemsci.org). This article is an open access article distributed under the terms and conditions of the Creative Commons Attribution license (http://creativecommons.org/licenses/by/4.0/). 